Aim of the study: The goal of our study was to assess the sexual functioning of patients undergoing mastectomy, five years after surgery, compared to a control group.

Material and methods: A cross-sectional study included 170 patients five years post mastectomy (group A1) and 149 healthy women (group A2) who had never been diagnosed with breast cancer. The study was conducted at the Oncology Centre in Bydgoszcz, at the Amazon Clubs, and at the University of the Third Age by the University of Economy in Bydgoszcz. Standardised questionnaires: the Female Sexual Function Index (FSFI) and Rosenberg's SES (self-esteem scale) were used. Results: Our study results show significantly worse sexual functioning in the domains pertaining to desire ( $p=$ $0.0015)$, arousal $(p=0.0052)$, lubrication $(p=0.0026)$, ability to reach orgasm $(p=0.0417)$, sexual satisfaction $(p=0.0142)$, and the presence of clinically significant sexual dysfunction ( $p=0.0028)$ among patients after amputation of the mammary gland. On the scale of pain relating to sexuality, there were no significant differences between the two groups (p> 0.05). The overall score in the FSFI questionnaire was also lower $(p=0.0066)$ among women after mastectomy. Highly statistically significant $(p<0.0001)$ differences in self-esteem were also noted between the two groups, with worse results observed in patients after mastectomy.

Conclusions: Diagnosis of sexual dysfunction in patients treated for breast cancer allows timely implementation of counselling and interventional therapy depending on the causal factors and individual preferences of patients.

Key words: mastectomy, sexual functioning, self-esteem.

Contemp Oncol (Pozn) 2020; 24 (2): 106-111 DOI: https://doi.org/10.5114/wo.2020.95876

\section{Sexual functioning and self-esteem in women after mastectomy - a single-centre, non-randomised, cross-sectional study}

\author{
Magdalena Tarkowska ${ }^{1}$, Iwona Głowacka-Mrotek ${ }^{2}$, Tomasz Nowikiewicz ${ }^{3,4}$, \\ Ewelina Monastyrska-Waszak ${ }^{3}$, Agata Gastecka ${ }^{5}$, Aleksander Goch ${ }^{1}$, \\ Wojciech Zegarski ${ }^{3}$
}

'Department of Physiotherapy, Ludwik Rydygier's Collegium Medicum in Bydgoszcz, Nicolaus Copernicus University in Torun, Bydgoszcz, Poland

2Department of Rehabilitation, Ludwik Rydygier's Collegium Medicum in Bydgoszcz, Nicolaus Copernicus University in Torun, Bydgoszcz, Poland

${ }^{3}$ Chair and Department of Surgical Oncology, Ludwik Rydygier's Collegium Medicum in Bydgoszcz, Nicolaus Copernicus University in Torun, Bydgoszcz, Poland

${ }^{4}$ Department of Clinical Breast Cancer and Reconstructive Surgery, Oncology Centre, Bydgoszcz, Poland

'Department of Urology, Ludwik Rydygier's Collegium Medicum in Bydgoszcz, Nicolaus Copernicus University in Torun, Bydgoszcz, Poland

\section{Introduction}

Epidemiological data indicate that breast cancer is now the most commonly diagnosed cancer in women living in developed countries [1]. Surgical and adjuvant breast cancer treatment may contribute to the "half-woman complex", reduced self-esteem and sense of competence, depressive disorders, and difficulties in accepting the change in physical conditions [2]. Fear of returning to sexual activity is also an important problem in this group of patients, because in our culture breasts belong to the attributes of femininity and motherhood. Therefore, negative self-perception of one's changed body and the fear of rejection by the partner may lie at the heart of sexual dysfunction [3]. Undesirable effects of anticancer treatment, such as medical menopause, hormonal disorders, weight change, bladder dysfunction, vaginal shortening, disorders of arousal and lubrication, or pain during intercourse, also affect sexual satisfaction and the relationship with one's partner $[4,5]$. Disruption of physical integrity of the female body often contributes to sexual dysfunction, even many years after therapy [6]. For many patients, returning to satisfactory sexual activity and regaining a sense of bodily attractiveness are measures of effectiveness of breast cancer treatment [4]. Literature indicates that patients receive insufficient support from medical staff when it comes to limiting sexual dysfunction after oncological treatment [5].

The aim of this work was to assess sexual functioning of patients undergoing mastectomy, five years after surgery, compared to a control group.

\section{Material and methods}

This cross-sectional study included 170 patients post mastectomy five years after surgery (group A1). Patients were recruited at the Oncology Centre in Bydgoszcz during a follow-up visit and at the Amazons Clubs of the KuyavianPomeranian Voivodeship during club meetings. The control group included 149 healthy women who had never been diagnosed with breast cancer - recruitment was carried out at the University of the Third Age at the University of Economy in Bydgoszcz (group A2). The study was conducted between 
February 2019 and December 2019 after obtaining approval of the CM UMK Bioethical Committee (No. 34/2019).

A diagnostic survey was used to assess sexual functioning and self-esteem in both groups. Standardised research tools, such as the Female Sexual Function Index (FSFI) and Rosenberg's SES (self-esteem scale) were used. The FSFI questionnaire is the most commonly used measuring tool for assessing sexual function in women around the world. The scale is available in many languages. It consists of 19 questions that enable assessment of sexual dysfunction in areas such as: arousal, ability to reach orgasm, desire, lubrication, pain problems associated with sexuality, and sexual satisfaction. The overall sexual functioning score allows for the detection of clinically significant sexual dysfunction. The higher the score, the better the performance on a given scale.

Rosenberg's SES was used to assess the overall level of self-assessment. It consists of 10 statements. By providing responses to questions on a four-point scale, the examined person determines to what extent he/she agrees with individual statements. The demographics of the sample were evaluated using our own questionnaire containing questions about age, education, place of residence, professional activity, marital status, number of children, duration of relationship, and socioeconomic status. Moreover, the use of neoadjuvant and adjuvant therapy, type of intervention performed on the regional lymphatic system, operated side, or partner's attitude towards reconstructive surgery were also identified in the mastectomy group.

Inclusion criteria:

- good general condition (ECOG 0-1),

- age 50-70 years,

- breast amputation 5 years ago (A1 only),

- married or in a partnership for a minimum of 7 years. Exclusion criteria:

- undergoing reconstructive breast surgery after mastectomy (group A1),

- bilateral mastectomy,

- no partner in the previous 4 weeks,

- active cancer,

- continuation of HTH adjuvant treatment (group A1),

- mental illness,

- body mass index above 35,

- gynaecological surgeries during the previous year.

\section{Statistical analysis}

Statistical analyses were conducted using PQStat statistical software 1.8.0.201. Sociodemographic (qualitative) data in the studied groups were compared using the $\chi^{2}$ test. Sociodemographic (quantitative) data in the studied groups were compared using the Mann-Whitney $U$ test. SES and FSFI scores were compared using the Mann-Whitney $U$ test. The $\chi^{2}$ test was used to assess significant sexual dysfunction in the compared groups. Testing probability of $p<0.05$ was considered significant, and testing probability of $p<0.01$ was considered highly significant.

\section{Results}

Selected sociodemographic and clinical characteristics of study population were identified. Distribution of such characteristics, such as education, place of residence, professional activity, socioeconomic status, marital status, number of children, and duration of relationship, did not differ significantly $(p>0.05)$ between the study groups. A statistically significant $(p=0.0411)$ difference between the groups was reported with regard to age. In women after mastectomy, the average age was 63.06 years, while in the control group it amounted to 64.83 years.

Among patients after breast amputation we also identified the use of neoadjuvant therapy, type of adjuvant treatment, type of surgical intervention performed on the regional lymphatic system, the operated side, and partner's opinion about breast reconstruction. Nearly $30 \%$ of patients were qualified for induction treatment. Adjuvant treatment was as follows: 89 patients were qualified for chemotherapy, 100 patients for radiotherapy, 43 for immunotherapy, and 101 for hormone therapy. Axillary lymphadenectomy (ALND) was performed in 113 patients, and 57 were referred for sentinel lymph node biopsy (SLNB). Right-sided mastectomy was performed in 75 women and left-sided in 95 women. Among mastectomy patients $(n=170), 27$ admitted that their partner urged them to undergo breast reconstruction surgery. The details are presented in Tables 1 and 2.

Self-esteem in the studied groups was assessed using Roosenberg's SES. Statistical analysis revealed highly significant differences between the results $(p<0.0001)$. In the mastectomy group the average score was 27.0, and in the control group it amounted to 30.8. Higher score in the control group means higher self-esteem compared to patients after breast amputation. Detailed data are presented in Table 3.

The following aspects of sexual functioning were assessed using a standardised FSFI questionnaire: desire, arousal, lubrication, ability to reach orgasm, sexual satisfaction, and sexual pain. In the domains of desire $(p=0.0015)$, arousal $(p=0.0052)$, and lubrication ( $p=0.0026)$ highly significant differences were noted between the studied groups, and significant differences were identified in the domains of ability to reach orgasm $(p=0.0417)$ and sexual satisfaction $(p=0.0142)$. In all of the above-mentioned domains, women after mastectomy demonstrated lower results than the control group, indicating poorer sexual functioning in a given domain. The two groups did not differ significantly with regard to the scores obtained in the sexual pain domain $(p>0.05)$. Detailed results are shown in Table 4.

In the next part of the study we analysed the overall results of sexual functioning between the study groups. There was a highly significant difference within the overall results of FSFI ( $p=0.0066)$ between the breast amputation patients and women from the control group. In the control group, the results were higher than those in the mastectomy group, which indicates poorer sexual functioning among patients after mastectomy. When considering these results qualitatively, i.e. divided by the presence or absence of dysfunction, a highly significant relationship $(p=0.0028)$ with the study group was found, i.e. clinically significant sexual dysfunction was more frequent (80\%) in women after mastectomy and less frequent (65\%) in 
Table 1. Sociodemographic (qualitative) characteristics of the studied groups (mastectomy vs. control group)

\begin{tabular}{|c|c|c|c|c|c|c|}
\hline \multirow[t]{2}{*}{ Independent variable } & \multirow[t]{2}{*}{ Characteristics } & \multicolumn{2}{|c|}{$\mathrm{A} 1$} & \multicolumn{2}{|c|}{$\mathrm{A} 2$} & \multirow[t]{2}{*}{$\chi^{2} ; p$} \\
\hline & & $n=170$ & $\%$ & $n=149$ & $\%$ & \\
\hline \multirow[t]{4}{*}{ Marital status } & Married & 134 & 78.82 & 104 & 69.8 & $3.94 ; 0.2685$ \\
\hline & Single & 3 & 1.76 & 2 & 1.34 & \\
\hline & Divorced & 9 & 5.29 & 12 & 8.05 & \\
\hline & Widow & 24 & 14.12 & 31 & 20.81 & \\
\hline \multirow[t]{4}{*}{ Education } & Primary & 11 & 6.47 & 8 & 5.37 & $0.4586,0.9279$ \\
\hline & Vocational & 49 & 28.82 & 45 & 30.20 & \\
\hline & Secondary & 89 & 52.35 & 75 & 50.34 & \\
\hline & Higher & 21 & 12.35 & 21 & 14.09 & \\
\hline \multirow[t]{2}{*}{ Residence } & City & 144 & 84.71 & 126 & 84.56 & $0.0012 ; 0.9720$ \\
\hline & Rural & 26 & 15.29 & 23 & 15.44 & \\
\hline \multirow[t]{2}{*}{ Professionally active } & Yes & 44 & 25.58 & 36 & 24.00 & $0.1252 ; 0.7235$ \\
\hline & No & 126 & 74.12 & 113 & 76.00 & \\
\hline \multirow[t]{4}{*}{ Socioeconomic status } & Very good & 26 & 15.29 & 22 & 14.77 & $0.20362 ; 0.9770$ \\
\hline & Good & 66 & 38.82 & 61 & 40.94 & \\
\hline & Average & 70 & 41.18 & 60 & 40.26 & \\
\hline & Low & 8 & 4.70 & 6 & 4.02 & \\
\hline \multirow[t]{2}{*}{ Treatment before surgery } & No & 120 & 70.59 & 0 & 0 & - \\
\hline & Yes & 50 & 29.41 & 0 & 0 & \\
\hline \multirow[t]{4}{*}{ Treatment after surgery } & $\mathrm{CHTH}$ & 89 & 52.35 & 0 & 0 & - \\
\hline & RTH & 100 & 58.82 & 0 & 0 & \\
\hline & HTH & 101 & 59.41 & 0 & 0 & \\
\hline & Immunotherapy & 43 & 25.29 & 0 & 0 & \\
\hline \multirow{2}{*}{$\begin{array}{l}\text { Partner urged for breast } \\
\text { reconstruction }\end{array}$} & No & 143 & 84.12 & 0 & 0 & - \\
\hline & Yes & 27 & 15.88 & 0 & 0 & \\
\hline \multirow[t]{2}{*}{ Operated side } & Right & 75 & 44.11 & 0 & 0 & - \\
\hline & Left & 95 & 55.88 & 0 & 0 & \\
\hline \multirow{2}{*}{$\begin{array}{l}\text { Surgical procedure } \\
\text { on the axillary fossa }\end{array}$} & SLNB & 57 & 33.53 & 0 & 0 & - \\
\hline & ALND & 113 & 66.47 & 0 & 0 & \\
\hline
\end{tabular}

A1 - mastectomy patients, A2 - control group, CHTH - chemotherapy, RTH - radiotherapy, HTH - hormone therapy, $p$ - significance level, SLNB - sentinel lymph node biopsy, ALND - axillary lymphadenectomy

Table 2. Sociodemographic (quantitative) characteristics in the study groups (mastectomy vs. control group)

\begin{tabular}{|c|c|c|c|c|c|c|}
\hline \multirow{2}{*}{$\begin{array}{l}\text { Descriptive } \\
\text { statistics }\end{array}$} & \multicolumn{2}{|c|}{ Age } & \multicolumn{2}{|c|}{ Number of children } & \multicolumn{2}{|c|}{ Duration of relationship } \\
\hline & $\mathrm{A} 1$ & $\mathrm{~A} 2$ & $\mathrm{~A} 1$ & $\mathrm{~A} 2$ & A1 & $\mathrm{A} 2$ \\
\hline M & 63.06 & 64.83 & 2.19 & 2.13 & 30.84 & 32.66 \\
\hline Me & 64 & 65 & 2 & 2 & 32 & 37 \\
\hline SD & 6.50 & 4.76 & 1.23 & 1.13 & 14.14 & 14.14 \\
\hline$Z$ statistics & 2.0427 & 0.4423 & 1.0593 & & & \\
\hline$p$ & 0.0411 & 0.6583 & 0.2895 & & & \\
\hline
\end{tabular}

A1 - mastectomy patients, A2 - control group, $p$ - significance level, SD - standard deviation, Me - median, M-arithmetic mean

women without an oncological history. Detailed results are presented in Table 5.

\section{Discussion}

This work compares the quality of sexual life among patients treated with mastectomy and healthy women of similar age. The standardised FSFI and Rosenberg's SES were used. The results of our study show significantly worse sexual functioning with regard to desire, arousal, lubrication, sexual satisfaction, ability to achieve orgasm, and presence of clinically significant sexual dysfunction among patients after amputation of mammary gland. The overall FSFI score was also lower in patients who had undergone breast amputation. Moreover, this group also 
Table 3. Rosenberg's self-assessment scale (SES) results in the study groups

\begin{tabular}{lcc} 
Descriptive statistics & \multicolumn{2}{c}{ SES } \\
\cline { 2 - 3 } & $\mathrm{A} 1$ & $\mathrm{~A} 2$ \\
$\mathrm{M}$ & 27.0059 & 30.8054 \\
$\mathrm{Me}$ & 27 & 30 \\
$\mathrm{SD}$ & 4.0943 & 3.9002 \\
Z statistics & 7.8867 & \\
P & $<0.0001$ & \\
A1 - mastectomy patients, A2 - control group, $p$ - significance level, \\
SD - standard deviation, Me - median, M-arithmetic mean
\end{tabular}

nosis among cancer patients $[9,12]$. Prospective studies conducted by Montazeriet et al. demonstrated significant deterioration in self-perception of one's body in mastectomy patients. This takes place even after the adverse symptoms of surgical and systemic treatment [13] have resolved. Both breast-conserving treatment as well as amputation affect patient functioning, not only physically, but also on psychosocial, emotional, and sexual levels [3]. Significant surgical intervention to the mammary glands can impair the integrity of physical as well as mental domains, which translates into the quality of sexual life [14].

Table 4. Results of the Female Sexual Function Index (FSFI) questionnaire in the studied groups

\begin{tabular}{|c|c|c|c|c|c|c|c|c|c|c|c|c|}
\hline \multirow{2}{*}{$\begin{array}{l}\text { Descriptive } \\
\text { statistics } \\
\text { Study group }\end{array}$} & \multicolumn{2}{|c|}{ FSFI I - desire } & \multicolumn{2}{|c|}{ FSFI II - arousal } & \multicolumn{2}{|c|}{$\begin{array}{l}\text { FSFI III - } \\
\text { lubrication }\end{array}$} & \multicolumn{2}{|c|}{ FSFI IV - orgasm } & \multicolumn{2}{|c|}{$\begin{array}{l}\text { FSFI V - sexual } \\
\text { satisfaction }\end{array}$} & \multicolumn{2}{|c|}{$\begin{array}{c}\text { FSFI VI - } \\
\text { dyspareunia }\end{array}$} \\
\hline & $\mathrm{A} 1$ & $A 2$ & $\mathrm{~A} 1$ & A2 & $\mathrm{A} 1$ & A2 & $\mathrm{A} 1$ & A2 & A1 & $A 2$ & $\mathrm{~A} 1$ & A2 \\
\hline M & 2.73 & 3.24 & 2.55 & 3.12 & 2.76 & 3.38 & 2.78 & 3.19 & 3.70 & 4.07 & 3.17 & 3.47 \\
\hline $\mathrm{Me}$ & 2.4 & 3 & 2.4 & 3.3 & 3 & 3.9 & 3.2 & 3.6 & 4 & 4.4 & 3.6 & 4.4 \\
\hline SD & 1.25 & 1.36 & 1.76 & 1.84 & 1.98 & 2.17 & 2.02 & 2.23 & 1.51 & 1.71 & 2.16 & 2.36 \\
\hline Z Statistics & \multicolumn{2}{|c|}{3.1845} & \multicolumn{2}{|c|}{2.797} & \multicolumn{2}{|c|}{3.0128} & \multicolumn{2}{|c|}{2.0367} & \multicolumn{2}{|c|}{2.4521} & \multicolumn{2}{|c|}{1.7204} \\
\hline$p$ & \multicolumn{2}{|c|}{0.0015} & \multicolumn{2}{|c|}{0.0052} & \multicolumn{2}{|c|}{0.0026} & \multicolumn{2}{|c|}{0.0417} & \multicolumn{2}{|c|}{0.0142} & \multicolumn{2}{|c|}{0.0854} \\
\hline
\end{tabular}

A1 - mastectomy patients, A2 - control group, $p$ - significance level, SD - standard deviation, Me - median, M - arithmetic mean

reported lower self-esteem compared to healthy women - the difference between the two groups was highly statistically significant.

A great advantage of our study is the fact that it was conducted on a large group of women many years after the end of oncological treatment, who were included on the basis of strict inclusion and exclusion criteria. Moreover, it should be stressed that the two compared groups did not differ with regard to demographic characteristics. Age is one exception - the average age among mastectomy patients was 63.06 years, while in healthy women it amounted to 64.83 years. Paradoxically, while women from the control group were older, their self-assessed sexual functioning and self-esteem scores were much better.

Surgical treatment of breast cancer patients, especially if mastectomy is necessary, can lead to development of the so-called "half-woman complex" and may contribute to lowering one's self-esteem [7]. According to Rosenberg, high self-esteem means respect for oneself as a human being, but also the ability to see our own limitations, without assuming that they make us inferior to others $[8,9]$. After mastectomy, the perception of one's own body and self-esteem changes. Women feel inferior, incomplete, fearful of returning to everyday life. In our study, Rosenberg's SES was used to evaluate self-esteem in patients five years after breast amputation and in healthy women of similar age. We found a statistically highly significant reduction in self-esteem among mastectomy patients compared to the control group. Lower self-esteem in patients after breast cancer treatment was also reported by many other authors [10, 11]. Many researchers also point out that self-esteem is an important factor in recovery and in returning to the level of activity from before the diag-
Table 5. The overall sexual functioning score and presence of significantly clinical sexual dysfunction

\begin{tabular}{|c|c|c|c|c|}
\hline \multirow{2}{*}{$\begin{array}{l}\text { Descriptive statistics } \\
M\end{array}$} & \multicolumn{4}{|c|}{$\begin{array}{l}\text { Overall FSFI score } \\
\text { A1 A2 }\end{array}$} \\
\hline & \multicolumn{2}{|c|}{17.6906} & \multicolumn{2}{|c|}{20.4725} \\
\hline Me & \multicolumn{2}{|c|}{18.85} & \multicolumn{2}{|c|}{22.3} \\
\hline SD & \multicolumn{2}{|c|}{9.1678} & \multicolumn{2}{|c|}{10.2913} \\
\hline$Z$ statistics & \multicolumn{4}{|c|}{2.7153} \\
\hline$p$ & \multicolumn{4}{|c|}{0.0066} \\
\hline $\begin{array}{l}\text { Presence of clinically significant } \\
\text { sexual dysfunction }\end{array}$ & $n$ & $\%$ & $n$ & $\%$ \\
\hline No & 34 & 20 & 52 & 34.9 \\
\hline Yes & 136 & 80 & 97 & 65.1 \\
\hline$\chi^{2} ; p$ & \multicolumn{4}{|c|}{$8.95 ; 0.0028$} \\
\hline
\end{tabular}

A1 - mastectomy patients, A2 - control group, $p$ - significance level,

FSFI - Female Sexual Function Index, SD - standard deviation, Me-median, $M$ - arithmetic mean

Factors that positively influence sexual satisfaction include acceptance of a new body image (both by a woman as well as her partner), strong emotional bonds, and a sense of attractiveness [7]. Sbitti et al. showed that treatment of breast cancer can contribute to sexual dysfunction [15]. In our study, the FSFI self-assessment questionnaire was used to evaluate factors influencing sexual satisfaction. We found significantly impaired functioning in all assessed domains - desire, arousal, lubrication, sexual satisfaction, sex-related pain - among patients who had undergone mastectomy five years prior, compared to women without a history of breast cancer. Moreover, clinically significant sexual dysfunction was noted in mastectomy patients compared to the control group. Similar 
results were obtained by other authors [3, 7, 10, 14, 16-18]. Observations made by Karabulut et al. in a group of 123 married women showed reduced sexual interest and sexual satisfaction among women after amputation of the mammary gland [18]. Aerts et al. compared sexual functioning among different groups of women: patients after mastectomy, patients after breast-conserving treatment $(\mathrm{BCT})$, and a control group of healthy women. Evaluation was performed before the procedure, and six and 12 months after the surgery. The results were as follows: 71\% of BCT patients and $64 \%$ of mastectomy patients declared their return to sexual activity six months and 12 months after surgery. In the BCT group, there was a marked increase in problems with arousal half a year after surgery. In mastectomy patients, a statistically significant deterioration in scores was noted at both follow-up dates in the following domains: arousal, sexual desire, and ability to reach orgasm, compared to preoperative results. Comparing the results of the control group and BCT patients, there were no significant differences in sexual functioning in either scale. Patients after mastectomy had significantly higher incidence of sexual dysfunction compared to the control group of women of similar age [3]. Fobiar et al. also pointed to a significant risk of developing dysfunction of a psychosexual nature in women after surgical treatment of breast cancer [17]. A study of 546 sexually active women aged 22-50 years, who declared to be married or in partnership for at least seven months before the diagnosis, found difficulty in accepting their changed body image as a consequence of mastectomy, reconstruction, hair loss, and risk of weight gain or weight loss. Nearly 160 sexually active women also reported problems in two or more areas of sexual functioning. The factors affecting the quality of intimate life were vaginal dryness, deterioration of mental health, and lack of understanding on the part of the partner [17]. Markopoulos et al. indicated that self-assessment of sexual functioning and self-esteem largely depends on the type of breast surgery and is worst among patients after mastectomy without immediate or deferred reconstruction [10]. Other authors indicated that the sexuality of patients after treatment of breast cancer is often overlooked, and treatment of sexual dysfunction is delayed [6]. Results reported by Hill et al. show that nearly $40 \%$ of patients undergoing therapy for breast cancer are interested in counselling on sexual functioning [19]. Other authors confirm that sex education of breast cancer patients brings tangible benefits and improves the quality of sexual life [14]. Some publications showed no effect of the extent of surgery on sexual life of women undergoing surgical treatment for breast cancer [16]. On the other hand, a study by Mroczek et al. from 2012 showed improvement in the quality of the sexual life of patients treated for breast cancer, especially if their intimate life was important to them before the procedure and there was a strong emotional bond between partners [7]. Long-term studies showed that a modern approach to women after mastectomy should also include professional activities aimed at preserving or regaining sexual function to the extent the patient finds satisfactory $[3,4]$.
Despite its high substantive value, our study has some limitations. It was planned as a retrospective, cross-sectional study; therefore, we do not know the results of self-assessment of sexual functioning among mastectomy patients before diagnosis of breast cancer and at various stages of antineoplastic treatment.

\section{Conclusions}

Our study showed significantly impaired self-esteem and significant deterioration in the quality of sexual life among women after mastectomy compared to women without an oncological history. Our study has shown that even several years after the end of treatment, patients need professional support to reduce adverse sequelae of cancer treatment and to aid in coping. It is important to discuss sexual problems at every stage of treatment, as well as to identify couples at risk of sexual dysfunction and provide them with professional assistance at the right time. Diagnosis of sexual dysfunction allows the adjustment of counselling and interventional therapy, depending on the causal factor and individual preferences of patients.

The authors declare no conflict of interest.

\section{References}

1. Głowacka-Mrotek I, Sowa M, Nowikiewicz T, Siedlecki Z, Hagner W, Zegarski W. Foot posture in female patients 5 years after breastconserving surgery: a case-control study. Breast Cancer 2018; 25: 325-333.

2. Almutairi KM, Mansour EA, Vinluan JM. A cross-sectional assessment of quality of life of breast cancer patients in Saudi Arabia. Public Health 2016; 136: 117-125.

3. Aerts L, Christiaens MR, Enzlin P, Neven P, Amant F. Sexual functioning in women after mastectomy versus breast conserving therapy for early-stage breast cancer: a prospective controlled study. Breast 2014; 23: 629-636.

4. Kowalczyk R, Nowosielski K, Cedrych I, Krzystanek M, Glogowska I, Streb J, Cook J, Lew-Starowicz Z. Factors Affecting Sexual Function and Body Image of Early-Stage Breast Cancer Survivors in Poland: A Short-Term Observation. Clinical Breast Cancer 2019; 19: 30-39.

5. Lindau ST, Abramsohn EM, Matthews AC. A manifesto on the preservation of sexual function in women and girls with cancer. Am J Obstet Gynecol 2015; 213: 166-174.

6. Jankowska M. Sexual functioning in young women in the context of breast cancer treatment. Rep Pract Oncol Radiother 2013; 18 : 193-200.

7. Mroczek B, Kurpas D, Grochans E, Kuszmar G, Rotter I, Zuttak-Baczkowska K, Karakiewicz B. Psychosexual functioning of women after the treatment of breast cancer. Psychiatr Pol 2012; 46: 51-61.

8. Parvan K, Tabrizi FJ, Rahmani A, Ghojazadeh M, Azadi A, Golchin M. The Relationship between Hope and Self-Esteem in Patients with Leukemia. J Caring Sci 2015; 4: 217-223.

9. Sivaperumal V, Mohd Sidik S, Lekhraj Rampal L, Fadhilah Ismail SI, Periasamy U. Self-esteem among cancer patients receiving chemotherapy in selected government state hospitals Peninsular Malaysia. Med J Malaysia 2019; 74:405-412.

10. Marcopoulus C, Tsaroucha AK, Kouskos E, Mantas D, Antonopou lou Z, Karvelis S. Impact of Breast Cancer Surgery on the Selfesteem and Sexual Life of Female Patients. J Int Med Res 2009; 3: $182-188$.

11. Curbow B, Somerfield M. Use of the Rosenberg Self-Esteem Scale with Adult Cancer Patients. J Psychosoc Oncol 2010; 9: 113-131. 
12. Mustaian KM, Katula JA, Gill DL, Roscoe JA, Lang D, Murphy K. Tai Chi Chuan, health-related quality of life and self-esteem: A randomized trial with breast cancer survivors. Support Care Cancer 2004; 12:871-876

13. Montazeri A, Vahdaninia M, Harirchi I, Ebrahimi M, Khaleghi F Jarvandi S. Quality of life in patients with breast cancer before and after diagnosis: an eighteen months follow-up study. BMC Cancer 2008; 8: 330-333.

14. Kashania FL, Vazirib S, Akbaric ME, Fard ZJ, Fare NS. Sexual Skills, Sexual Satisfaction and Body Image in Women with Breast Cancer. Procedia Soc Behav Sci 2014; 159: 206-213.

15. Sbitti Y, Kadiri H, Fadoukhair ZK, et al. Breast cancer treatment and sexual dysfunction: Moroccan women's perception. BMC Womens Health 2011; 13: 11-29.

16. Słowik AJ, Jablonski MJ, Michałowska-Kaczmarczyk AM, Jach R. Study of the quality of life of women with breast cancer, with a particular focus on sexual satisfaction and prospects for the future and body image depending on the method of surgical treatment used. Psychiatr Pol 2017; 51: 871-888.

17. Fobiar P, Stewart SL, Chang S, D'Onofrio C, Banks PJ, Bloom JR. Body image and sexual problems in young women with breast cancer. Psychooncology 2006; 15: 579-594.

18. Karabulut N, Erci B. Sexual desire and satisfaction in sexual life affecting factors in breast cancer survivors after mastectomy. J Psychosoc Oncol 2009; 27: 333-343.

19. Hill EK, Sandbo S, Abramsohn E, et al. Assessing gynecologic and breast cancer survivors' sexual health care needs. Cancer 2011; 117: 2643-2651.

\section{Address for correspondence}

\section{Magdalena Tarkowska}

Department of Physiotherapy

Ludwik Rydygier's Collegium Medicum in Bydgoszcz

Nicolaus Copernicus University in Torun

Marii Skłodowskiej-Curie St. 9

85-094 Bydgoszcz, Poland

e-mail: magdalena.sowa@cm.umk.pl

Submitted: 12.03 .2020

Accepted: 30.03 .2020 